\title{
Fine Structure and Biochemical Mechanisms Underlying Nigrostriatal Inclusions and Cell Death after Proteasome Inhibition
}

\author{
Francesco Fornai, ${ }^{1,2}$ Paola Lenzi, ${ }^{1}$ Marco Gesi, ${ }^{1}$ Michela Ferrucci, ${ }^{1}$ Gloria Lazzeri, ${ }^{1}$ Carla L. Busceti, ${ }^{2}$ Riccardo Ruffoli, ${ }^{1}$ \\ Paola Soldani, ${ }^{1}$ Stefano Ruggieri, ${ }^{2,3}$ Maria G. Alessandrì, ${ }^{4}$ and Antonio Paparelli ${ }^{1}$ \\ ${ }^{1}$ Department of Human Morphology and Applied Biology, University of Pisa, I-56100 Pisa, Italy, ${ }^{2}$ Istituto di Ricovero e Cura a Carattere Scientifico, Istituto \\ Neurologico Mediterraneo Neuromed Pozzilli, I-86100, Italy, ${ }^{3}$ Department of Neurological Sciences, University of Rome "La Sapienza," I-00185 Rome, Italy, \\ and ${ }^{4}$ Instituto di Ricovero e Cura a Carattere Scientifico, Stella Maris Scientific Institute, I-00185 Pisa, Italy
}

\begin{abstract}
Mutation of genes encoding for various components of a metabolic pathway named the ubiquitin-proteasome system (UP) leads to inherited forms of Parkinson's disease (PD), whereas various components of the UP are constantly present within neuronal inclusions, Lewy bodies, that characterize most genetic and sporadic forms of PD. It has been hypothesized that impairment of this metabolic pathway might be a common mechanism for the onset of PD, and a recent study demonstrated a dysfunction of the UP system within the substantia nigra of patients affected by sporadic PD. In search for the mechanisms underlying the selective toxicity for nigral neurons after inhibition of the UP system, we explored the selective effects after striatal microinfusions of lactacystin or epoxomycin and potential retrograde changes within the ipsilateral substantia nigra. We found that neurotoxicity was selective for striatal dopamine (DA) components and led to retrograde apoptosis within nigral DA cells, which developed neuronal inclusions staining for antigens of the UP system. We found the same ultrastructural features characterizing inclusions obtained in vivo and in vitro after UP inhibition. In vivo, lactacystin- epoxomycin-induced toxicity was suppressed by inhibiting DA synthesis. Similarly, in vitro inclusions and apoptosis were prevented by reducing endogenous DA. On the other hand, toxicity of proteasome inhibition was enhanced by drugs augmenting DA availability: L-3,4-dihydroxyphenylalanine, monoamine oxidase blockers, and DA $\beta$-hydroxylase blockers.

These findings demonstrate that impairment of the UP system produces cell death and neuronal inclusions selectively for DAcontaining neurons that depend on the occurrence of endogenous DA.
\end{abstract}

Key words: lactacystin; epoxomycin; neuronal inclusions; nigrostriatal damage; Parkinson's disease; ubiquitin-proteasome pathway; $\alpha$-synuclein

\section{Introduction}

The ubiquitin-proteasome (UP) system is an ubiquitary, multienzymatic proteolytic pathway that removes misfolded, ubiquitinated proteins (Ciechanover et al., 2000), including internalized receptor (Shenoy et al., 2001). Recently, mutations of genes encoding for proteins of the UP were found to be responsible for inherited forms of Parkinson's disease (PD) (Polymeropoulos et al., 1997; Kitada et al., 1998; Leroy et al., 1998; Shimura et al., 2000). These mutations decrease UP activity (Kitada et al., 1998; Leroy et al., 1998; Chung et al., 2001; Steece-Collier et al., 2002). Although they are rare events, these mutations involve three known gene products: $\alpha$-synuclein (PARK 1), parkin (PARK 2),

Received Jan. 23, 2003; revised Aug. 11, 2003; accepted Aug. 13, 2003.

This work was supported by a grant from Ministero della Sanità (Ricerca Finalizzata 237/02) (F.F.). We thank Dr. Thomas Sudhof (University of Texas, Dallas, TX) for the gift of $\alpha$-synuclein antibodies and Dr. Larry Schmued (National Center for Toxicological Research, United States Food and Drug Administration, Jefferson, AR) for the Fluoro Jade-B. Sauro Dini and Claudio Policicchio (University of Pisa, Pisa, Italy) are gratefully acknowledged for their skillful technical assistance.

Correspondence should be addressed to Francesco Fornai, Department of Human Morphology and Applied Biology, Via Roma 55, I-56100 Pisa, Italy. E-mail: f.fornai@med.unipi.it.

Copyright $\odot 2003$ Society for Neuroscience $\quad$ 0270-6474/03/238955-12\$15.00/0 and ubiquitin-C-hydrolase-L1 (Uch-L1, PARK 5), which are presently under intense investigation (Lansbury and Brice, 2002).

In keeping with this, intracellular inclusions known as Lewy bodies (LBs), a pathological hallmark of sporadic PD, stain specifically for proteins associated with UP (Gai et al., 2000; McNaught et al., 2002b), including $\alpha$-synuclein (Spillantini et al., 1997), a protein that does not belong to the UP but interacts with ubiquitin as a substrate for the UP (Conway et al., 2001; Sulzer, 2001), Uch-L1 (Liu et al., 2002), and parkin (Shimura et al., 2001), an E3 ubiquitin-protein ligase. Convergence of genetic and sporadic forms of PD in altering and/or aggregating components or substrates of the UP system indicates that a failure of this multi-enzymatic complex might represent a final common pathway in the pathogenesis of PD. Lending substance to this hypothesis, McNaught et al. $(2001,2003)$ found an impairment of the proteasome in humans affected by sporadic $\mathrm{PD}$.

The present study was designed to analyze in vivo and in vitro the effects of exogenous inhibition of the UP pathway and the potential molecule responsible for selective toxicity.

In vivo, we produced a focal inhibition of the UP by microinfusing specific proteasome inhibitors in the neostriatum to (1) 
demonstrate whether UP inhibition in vivo leads to neuronal damage, (2) analyze whether this damage is selective for dopamine (DA) neurons compared with other striatal components, (3) measure whether blocking the UP in the striatum leads to retrograde degenerative processes in the substantia nigra, and (4) observe whether UP inhibition is accompanied by neuronal inclusions. In vitro, we reproduced the same effects observed in vivo by adopting the PC12 cell line as reported previously (Rideout et al., 2001). We profited from this simple model to investigate the following points: (1) the parallelism between inclusions obtained in vitro and those observed in vivo; (2) the parallelism between proteasome inhibition and inclusion formation; (3) whether epoxomycin, which specifically inhibits the chymotrypsin-like activity of the proteasome, reproduces the same effects induced by lactacystin; (4) the fine ultrastructure of inclusions; (5) why proteasome inhibition leads to a damage that is particularly severe for DA-producing cells; (6) the biochemical mechanisms or molecule underlying selective neurotoxicity.

This latter point is crucial, because failure of the UP activity in genetic PD is ubiquitous, whereas neuropathology of PD mostly affects nigrostriatal DA neurons (Forno, 1996; Chung et al., 2001).

\section{Materials and Methods \\ In vivo experiments}

Animals. Male Sprague Dawley rats, weighting 200-250 gm, were obtained from Harlan Italy (San Pietro al Natisone, Italy). Animals received food and water ad libitum and were kept under strictly controlled environmental conditions ( $12 \mathrm{hr}$ light/dark cycle, with light on between 7:00 A.M. and 7:00 P.M.; room temperature, $21^{\circ} \mathrm{C}$ ). During all of the experimental procedures, rats were treated in accordance with the Guidelines for Animal Care and Use of the National Institute of Health. All efforts were made to reduce animal suffering and the number of animals used.

Surgery and microinfusions. Rats were deeply anesthetized with chloral hydrate $(400 \mathrm{mg} / \mathrm{kg}$, i.p.) and placed in a Kopf stereotaxic apparatus (David Kopf Instruments, Tujunga, CA). For each animal, an injection cannula $(0.36 \mathrm{~mm}$ external diameter, $17 \mathrm{~mm}$ long; Plastics One, Roanoke, VA) was inserted through a hole drilled in the skull, in the central part of the right striatum using the following coordinates (in $\mathrm{mm}$ ): anteroposterior (AP), +0.48 ; mediolateral (ML), \pm 3.0 ; dorsoventral (DV), -5.6 (Paxinos and Watson, 1986). The cannula was connected via a polyethylene tubing to a Hamilton $10 \mu \mathrm{l}$ syringe driven by a microinfusion pump (Harvard Apparatus, Holliston, MA). The specific proteasome inhibitors lactacystin (Sigma, St. Louis, MO) or epoxomycin (Calbiochem, San Diego, CA) were inserted in the right striatum (see Fig. 1a) ( $n=48,24$ infused with lactacystin and 24 with epoxomycin), whereas the left symmetric side was microinfused with saline $(n=16)$, sham operated $(n=16)$, or left intact $(n=16)$. Infusions were performed during the surgery, when a solution of lactacystin or epoxomycin (100 $\mu \mathrm{M}$ ) was delivered at a flow rate of $100 \mathrm{nl} / \mathrm{min}$ for $10 \mathrm{~min}$. To evaluate the effects of two additional doses of both inhibitors $(10 \mu \mathrm{M}$ and $1000 \mu \mathrm{M})$, we included an additional 48 rats $(n=48,24$ for each dose, divided in four groups; two doses for each inhibitor, leading to six rats per group). We could not find any additional proteasome inhibition rising the concentration between 100 and $1000 \mu \mathrm{M}$ (see Results).

To measure the role of DA synthesis on neurotoxicity induced by proteasome inhibitors (at the concentration of $100 \mu \mathrm{M}$ ), in an additional three groups ( $n=8$ each), we administered systemically the tyrosine hydroxylase inhibitor $\alpha$-methyl-p-tyrosine $(\alpha \mathrm{MpT})(150 \mathrm{mg} / \mathrm{kg}$, i.p.; Sigma), at $4 \mathrm{hr}$ before infusing saline, lactacystin, or epoxomycin (same doses reported above). Similarly, additional groups $(n=8$ each) were administered L-3,4-dihydroxyphenylalanine (L-DOPA) (100 mg/kg free base, $30 \mathrm{~min}$ before proteasome inhibitors or saline) or pargyline hydrocloride ( $75 \mathrm{mg} / \mathrm{kg}, 30 \mathrm{~min}$ before proteasome inhibitors or saline). These doses are known to produce in vivo an increase in striatal DA availability or a blockade of striatal monoamine oxidase activity, respectively (Finberg et al., 1995; Fornai et al., 1999). After surgery, rats were allowed to recover in their home cage with access to food and water ad libitum. Seven days after microinfusions, rats were killed, and the brains were processed for biochemistry, light microscopy, and electron microscopy.

For morphology, deeply anesthetized rats were perfused using $0.1 \%$ glutaraldehyde plus $2 \%$ paraformaldehyde in PBS, $\mathrm{pH}$ 7.3. Brains were kept overnight in the same solution. Rats undergoing biochemical assay were instead decapitated, and their brain was quickly removed to dissect both striatum and substantia nigra (see both sides of Fig. 1a,b) on icecold saline. The samples were then homogenized in $600 \mu \mathrm{l}$ (striatum) or $200 \mu \mathrm{l}$ (nigra) of $0.1 \mathrm{~N}$ perchloric acid, from which a $50 \mu \mathrm{l}$ aliquot was used for protein assay, and the rest was centrifuged at $10,000 \times g$ for 10 min and further analyzed as described later.

\section{In vitro experiments}

Cell cultures and treatments. The rat pheochromocytoma cell line PC12 was obtained from the American Type Culture Collection (Manassas, VA) and grown in RPMI 1640 medium supplemented with heatinactivated $10 \%$ horse serum and $5 \%$ fetal bovine serum, including penicillin $(50 \mathrm{IU} / \mathrm{ml})$ and streptomycin $(50 \mathrm{mg} / \mathrm{ml})$. Cells were grown in 75 $\mathrm{cm}^{2}$ tissue culture flasks and maintained in a humidified atmosphere of $5 \% \mathrm{CO}_{2}$ at $37^{\circ} \mathrm{C}$. The medium was changed every $3 \mathrm{~d}$ and maintained at the culture conditions described above. Experiments took place during the log phase of cells growth. At this time, PC12 cells were seeded in six-well plates at $5 \times 10^{5}$ cells at a final volume of $1 \mathrm{ml} /$ well and incubated at $37^{\circ} \mathrm{C}$ in $5 \% \mathrm{CO}_{2}$ for $72 \mathrm{hr}$.

Lactacystin-epoxomycin were left for $24 \mathrm{hr}$ in the cell culture based on pilot time course experiments. For this time of exposure, we measured the effects of various doses ranging from 0.1 to $50 \mu \mathrm{M}$.

For measuring proteasome inhibition, lactacystin-epoxomycin at doses ranging from 0.01 to $20 \mu \mathrm{m}$ were added to the cell culture for $4 \mathrm{hr}$ before the assay (see the next paragraph).

On the basis of the in vitro dose-response studies on proteasome inhibition (see Fig. $5 a-c$ ), formation of inclusions (see Fig. $6 a$ ), induction of apoptosis (see Fig. 6b), DA levels in the medium, and cell pellet (see Fig. $6 c, d$, respectively), additional experiments were performed exposing cells to $10 \mu \mathrm{M}$ lactacystin for $24 \mathrm{hr}$, starting at $4 \mathrm{hr}$ after exposure to saline or various drugs acting at different steps of DA metabolism: the DAdepleting agent, reserpine (methyl reserpate acid ester; 50 nм; Sigma); the inhibitor of DOPA-decarboxylase, carbidopa (20 $\mu \mathrm{M}$; Sigma); the inhibitor of DA $\beta$-hydroxylase, fusaric acid ( $1 \mu \mathrm{M}$; Sigma); and the nonselective irreversible inhibitor of monoamine oxidase, pargyline hydrocloride (100 $\mu \mathrm{M}$; Sigma). Moreover, we supplied methyl-L-DOPA hydrocloride (500 $\mu \mathrm{M}$; Sigma) as a DA precursor. On the basis of the effects on DA levels, we also evaluated the effects of a selective DA uptake inhibitor (GBR 12909 dihydrochloride; $1 \mu \mathrm{M}$; Sigma). Lactacystin-epoxomycin solutions were prepared by dissolving the powder in water as a $1 \mathrm{~mm}$ stock solution, which was freshly diluted at various concentrations in the culture medium. The other drugs were dissolved directly in the culture medium.

At the end of experiments, PC12 cells were variously processed: for electron microscopy, they were centrifuged, fixed, and embedded in Epon-Araldite; for light microscopy, they were centrifuged again, and pellets were dissolved in buffer, applied on glass slides by cytospin $(12,000 \times g$ for $10 \mathrm{~min})$, and processed for various staining. For the biochemical assays, we used both the centrifuged cell pellets and the culture medium. In the first case, cell pellets were resuspended in $0.1 \mathrm{~N}$ perchloric acid, sonicated, and centrifuged again. We compared data obtained using protein assay (expressing results per protein unit) with those simply referring to the initial volume of the cell culture. Indeed, we were using a homogeneous cell line with various dishes growing in log phase for the same amount of time and containing a similar cell number (counted before starting the experiment). In these conditions, we found expressing amount of DA and metabolites per protein unit to be sometime misleading. In fact, occurrence of drug-induced cell death determined a comparable loss of protein content and catecholamine levels, making the assay not different from controls. Therefore, we preferred to refer the DA-metabolite content to the initial volume of the cell culture instead of protein units. Apart from measuring intracellular catecholamine levels, we also collected the culture medium (450 $\mu$ l of culture 
medium were added in $50 \mu \mathrm{l}$ of $1 \mathrm{~N}$ perchloric acid, to reach a final $0.1 \mathrm{~N}$ perchloric acid solution), which was then directly injected into the HPLC. Measuring catecholamines in the pellets and the medium allowed us a simultaneous detection of intracellular and extracellular levels of DA and metabolites.

\section{Morphology}

Light microscopy. For in vivo experiments, brain slices ( $20 \mu \mathrm{m}$ thick) were cut on a cryostate to obtain serial slices extending $\pm 0.4 \mathrm{~mm}$ anteroposteriorly from the point of insertion of the cannula (see Fig. 1a). Moreover, to evaluate the retrograde effects of lactacystin-epoxomycin on the nigrostriatal DA system, brain sections at the level of the substantia nigra were collected (see Fig. 1b). Slides from striatum and substantia nigra were alternatively stained with hematoxylin-eosin (H\&E) and immunocytochemistry (see below). Within the striatum, densitometric analysis and cell count were performed within a total area extending rostrocaudally $0.8 \mathrm{~mm}$ (from AP +0.20 to AP +1.0 ), whereas mediolaterally, we proceeded from the medial border of the considered area $(3.2 \mathrm{~mm}$ lateral to the midline) to the lateral border of the striatum. Finally, the dorsoventral extent started at the striatal dorsal border going down to $6.6 \mathrm{~mm}$ below the skull (see Fig. $1 a$, dotted area). Brain slices aimed at analyzing the substantia nigra extended $0.7 \mathrm{~mm}$ rostrocaudally (from AP -5.60 to $\mathrm{AP}-6.30$ ) (see Fig. $1 b$, red-squared area). At the nigral level, we also stained sections using the Fluoro Jade-B (gift from Larry Schmued, National Center for Toxicological Research, United States Food and Drug Administration, Jefferson, AR). Briefly, according to the original method of Schmued and Hopkins (2000), slides were rinsed in different solutions in the following order: $1 \%$ sodium hydroxide in $80 \%$ alcohol ( $5 \mathrm{~min}$ ), $70 \%$ alcohol $(2 \mathrm{~min}$ ), distilled water ( $2 \mathrm{~min}$ ), $0.06 \%$ potassium permanganate (10 min), and kept in the Fluoro Jade-B solution for $20 \mathrm{~min}$. This consisted in $98 \mathrm{ml}$ of a freshly prepared $0.0004 \%$ solution of the Fluoro Jade-B powder in $0.1 \%$ acetic acid. Fluoro Jade-B-stained cells emit a typical yellow color when examined using an epifluorescent microscope with excitation light set at $450 \mathrm{~nm}$.

Symmetric areas from injected and control sides as well as shamlesioned and non-operated controls were compared. For in vitro experiments, we directly processed for H\&E and immunocytochemistry (see below) glass slides in which suspended cells from the pellet were applied by cytospin. They were directly observed at light microscopy, and counts were performed from 10 sister dishes to obtain a mean \pm SEM for each experimental condition.

Electron microscopy. Microinfused striata were carefully dissected, and specimens of $0.4 \mathrm{~mm}^{3}$ were taken from the dotted areas of Figure $1 a$. Analogous samples from contralateral, sham-lesioned, and nonoperated striata were also dissected and used as controls. For the substantia nigra, we again dissected samples using a micropunch procedure; sections of $100 \mu \mathrm{m}$ were cut using a vibratome and stained with methylene blue to verify the outcome of the dissection (see also Fornai et al., 2001).

For plane electron microscopy, specimens were postfixed in $1 \% \mathrm{OsO}_{4}$ buffered solution, dehydrated in ethilic alcohol, and embedded in EponAraldite. Ultrathin sections were stained with uranyl acetate and lead citrate and were finally examined with a Jeol (Tokyo, Japan) Jem 100SX transmission electron microscope.

PC12 cells obtained after centrifugation at $1000 \times g$ for 5 min were fixed in $0.1 \%$ glutaraldehyde- $2 \%$ paraformaldehyde in PBS, postfixed, and processed as described above. For scanning electron microscopy, cell pellets were layered in a poly-L-lysine-coated coverslips and dehydrated in ethanol series, and, after reaching the critical point by $\mathrm{CO}_{2}$ drying, they were coated with gold and examined by a Jeol 5200 scanning electron microscope.

\section{Immunocytochemistry}

We used antibodies against the DA transporters (DAT) glutamic acid decarboxylase-67 (GAD-67) (Chemicon, Temecula, CA), tyrosine hydroxylase (TH) (Sigma), glial fibrillary acidic protein (GFAP) (Sigma), ubiquitin (Sigma), ubiquitin-activating enzyme E1 (Chemicon), parkin (Chemicon), and $\alpha$-synuclein (gift from Dr. Thomas Sudhof, University of Texas, Dallas, TX).
Samples were examined at both light and electron microscopy. For light microscopy, all dilutions of peroxidase-revealed primary antibodies were 1:1000, except from $\alpha$-synuclein and parkin primary antibodies, which were diluited 1:500. The dilution of E1 primary antibody was 1:50. The secondary biotinylated antibodies (Vector Laboratories, Burlingame, CA) were used at a dilution of 1:200, followed by incubation with $\mathrm{ABC}$ kit and diaminobenzydine (Vector Laboratories). Fluoresceinconjugated secondary antibodies (Vector Laboratories) were used at dilution of 1:300, whereas the Cy3-conjugated secondary antibody (Chemicon) was used at dilution of 1:400. The sections were observed using a Wetzlar Orthoplan (Leitz, Wetzlar, Germany) light microscope.

Postembedding immunoelectron microscopy was performed on ultra-thin sections that were deosmicated with aqueous solution of $\mathrm{Na}-$ metaperiodate and incubated for $24 \mathrm{hr}$ at $4^{\circ} \mathrm{C}$ with primary antibodies in buffer solution A (PBS, $1 \%$ goat-serum, and $0.2 \%$ saponin). All primary antibodies were diluted 1:100. Then, sections were incubated with goldconjugated secondary antibodies (gold particles, 10-15 $\mathrm{nm}$ ) diluted 1:50 in buffer solution A for $1 \mathrm{hr}$ at room temperature or they were revealed with peroxidase as described for light microscopy. Finally, sections were fixed with $1 \%$ glutaraldehyde, stained with uranyl acetate and lead citrate, and examined at transmission electron microscopy (TEM).

\section{Apoptosis assays}

Occurrence of apoptosis in vivo and in vitro was performed using the gold standard (transmission and scanning electron microscopy). PC12 and nigral apoptotic cells were identified using electron microscopy (for the procedure, see above). We also evaluated apoptosis at light microscopy (for cell count, see above). We joined these procedures to have broader samples for cell counts when we found that light microscopic evidence was validated by combining electron microscopy data. In particular, at light microscopy, we used the fluorescent method for condensed chromatin with bisbenzimide trihydrochloride (Hoechst-33258; Sigma) (Haimovitz-Friedman et al., 1994). Briefly, PC12 cells were washed with PBS and fixed in 3\% parafolmaldehyde. After $10 \mathrm{~min}$, the fixative solution was removed, and the cells were washed with PBS, resuspended in $20 \mu \mathrm{l}$ of PBS containing $8 \mu \mathrm{g} / \mathrm{ml}$ bisbenzimide trihydrochloride, and incubated at room temperature for $15 \mathrm{~min}$. Aliquots of the cells $(10 \mu \mathrm{l})$ were placed on glass slides and counted for apoptosis using light microscopy. For in vivo studies, slides of the substantia nigra from $4 \%$ paraformaldehyde-perfused rats were exposed for 15 min to bisbenzimide trihydrochloride ( $8 \mu \mathrm{g} / \mathrm{ml}$ in PBS), washed, covered, and counted. As an additional approach, apoptosis was determined by semiquantitative assay of DNA laddering. For each sample, $1.5 \times 10^{6}$ cells were collected and centrifuged at $10,000 \times g$ for 5 min. Cells were lysed in TE buffer ( $1 \mathrm{~mm}$ EDTA and $10 \mathrm{~mm}$ Tris-base, $\mathrm{pH} 7.5$ ) for $90 \mathrm{~min}$ at $4^{\circ} \mathrm{C}$; cell lysates were centrifuged again at $15,000 \times g$ for $1 \mathrm{hr}$ at $4^{\circ} \mathrm{C}$, and clear supernatants containing fragmented chromatin were digested at $42^{\circ} \mathrm{C}$ for $30 \mathrm{~min}$ with proteinase $\mathrm{K}(200 \mu \mathrm{g} / \mathrm{ml})$. Equal volume of phenol, chloroform, and isoamyl alcohol were added to samples, vigorously shaken for $30 \mathrm{sec}$, and centrifuged at $15,000 \times g$ for $10 \mathrm{~min}$. Supernatants were collected and mixed with $100 \mu \mathrm{l}$ of $5 \mathrm{M} \mathrm{NaCl}, 1 \mathrm{ml}$ of ethanol $\left(4^{\circ} \mathrm{C}\right)$, and $1 \mu \mathrm{l}$ of glycogen. The suspensions were kept at $-20^{\circ} \mathrm{C}$ overnight to precipitate DNA fragments and then centrifuged at $15,000 \times g$ for 30 min; the supernatants were discarded, and the pellets were washed with $70 \%$ ethanol and dried under air flow.

Each sample was resuspended in TE buffer containing $1 \mathrm{mg} / \mathrm{ml}$ boiled bovine pancreatic RNAase, incubated at $40^{\circ} \mathrm{C}$ for $1 \mathrm{hr}$, and then mixed with DNA sample buffer (15 mm EDTA, pH 8.0, 0.1\% SDS, $0.025 \%$ xylene cyanole, $0.025 \%$ bromophenol blue, and $0.5 \%$ glycerol). Separation of DNA fragments was obtained by electrophoresis in $1 \%$ agarose gel, in Tris-EDTA-acetate buffer (32 mm Tris-base, $1 \%$ glacial acetic acid, and 1 mm EDTA), and bands were visualized by ethidio bromide staining under UV light.

\section{Monoamine assay}

In each experimental group (both in vivo and in vitro experiments), after various processing, we injected $20 \mu \mathrm{l}$ of the clear supernatant into a reverse-phase, ion-pairing HPLC, coupled with two electrochemical detectors, as reported previously (Fornai et al., 1999), to measure levels of 
$\mathrm{DA}$, serotonin (5-HT), norepinephrine (NE), dihydroxyphenylacetic acid (DOPAC), and homovanillic acid. For striatal and nigral samples, an aliquot of $50 \mu \mathrm{l}$ was assayed for proteins, whereas values for cell pellets were expressed on the basis of the initial volume (see above).

\section{Assay of proteasome activity}

We measured this activity both in vitro and in vivo. Briefly, in vitro, we measured a doseresponse effect exposing cell cultures to either lactacystin or epoxomycin at a concentration ranging between 0.01 and $20 \mu \mathrm{M}$. After $4 \mathrm{hr}$ of exposure, cell cultures were collected, washed with PBS to remove the proteasome inhibitors, and stored at $-80^{\circ} \mathrm{C}$ until analysis. Cells were slowly thawed, kept at $4^{\circ} \mathrm{C}$, resuspended in a buffer (in mm: 10 Tris- $\mathrm{HCl}, \mathrm{pH} 7.8,0.5$ dithiothreitol, $5 \mathrm{ATP}$, and $5 \mathrm{MgCl}_{2}$ ), and sonicated with a Microson ultrasonic cell disruptor (Ultra Heat Systems) three times for $20 \mathrm{sec}, 20 \mathrm{sec}$ apart. Protein content of homogenates was determined. Cell homogenates containing equal amount of proteins $(10-60 \mu \mathrm{l})$ were analyzed for proteasome activity. For in vivo analysis, samples of striata microinfused with either lactacystin or epoxomycin [including either tissue surrounding the tip of the cannula (TIP) or the close dorsolateral striatum (DLS), both topographically defined at the beginning of Materials and Methods and shown in Fig. 1a] were compared with the symmetric part of the contralateral striata or saline-injected controls. The effects of three different concentrations (10, 100 , and $1000 \mu \mathrm{M}$ ) of both inhibitors were compared in samples from DLS (see Fig. 1). Samples were removed on ice at $4 \mathrm{hr}$ after the end of infusion with proteasome inhibitors and stored at $-80^{\circ} \mathrm{C}$ until analysis. Samples were slowly thawed on ice and homogenized in $100 \mu \mathrm{l}$ of ice-cold $10 \mathrm{~mm}$ Tris-HCl, pH 7.8, containing 1 mM EDTA. Protein content from each striatal sample was determined. Additional samples were collected from DLS at 8,24 , and $72 \mathrm{hr}$ from a small group $(n=4)$ of rats to establish the time duration of proteasome inhibition in vivo with both lactacystin and epoxomycin at the plateau concentration to inhibit the proteasome in vivo $(100 \mu \mathrm{M})$.

The 20S Proteasome Activity Assay kit (Chemicon) was used to measure the chymotrypsin-like activity. The post-glutamyl peptidase activity [or peptidyl-glutamyl-peptide hydrolyzing (PGPH) activity] was measured using Cbz-Leu-Leu-Glu-AMC (Sigma), and the trypsin activity was measured using Boc-Leu-Ser-Thr-Arg-AMC (Sigma). In all cases, the activity was measured by detection of the fluorophore 7-amido-4methylcoumarin (AMC) after cleavage from the various synthetic fluorogenic peptides: Leu-LeuVal-Tyr-AMC (for chymotrypsin activity); CBZ-Leu-Leu-Glu-AMC (for PGPH activity); and Boc-Leu-Ser-ThrArg-AMC (for trypsin activity).

\section{Turning behavior}

Rats microinfused unilaterally with proteasome inhibitors (two groups, $n=5$ for lactacystin and $n=5$ for epoxomycin) were systemically injected with either apomorphine $(0.1 \mathrm{mg} / \mathrm{kg})$ or methamphetamine $(5$ $\mathrm{mg} / \mathrm{kg}$ ). The challenge was performed at 7,21 , and $28 \mathrm{~d}$ after striatal microinfusions. An additional group of rats $(n=10)$ was microinfused with 6-hydroxydopamine (6-OHDA) in the substantia nigra at the dose of $8 \mu \mathrm{g}$ (infused during $4 \mathrm{~min}$ ). Microinfusions occurred during chloral hydrate anesthesia according to the following coordinates (in $\mathrm{mm}$ ): AP,

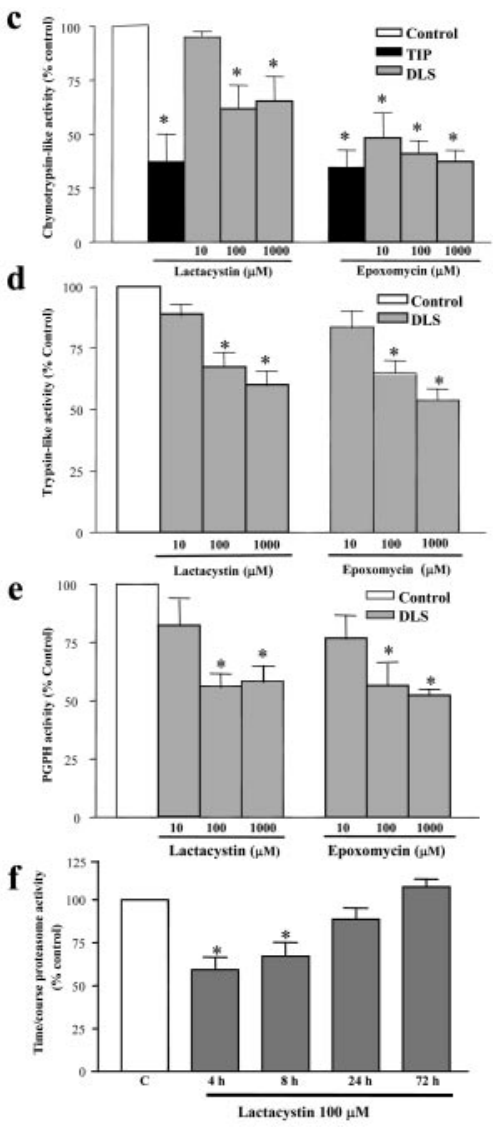

Figure 1. Unilateral striatal infusion of lactacystin-epoxomycin produces ipsilateral loss of striatal proteasome activity. The specific proteasome inhibitors lactacystin or epoxomycin $(10,100$, and $1000 \mu \mathrm{M})$ were infused for 10 min unilaterally in the centra paring striatum using the coordinates AP, +0.48 mm; ML, +3.0 mm; and DV, $-5.6 \mathrm{~mm}$ (Paxinos and Watson, 1986), whereas the left symmetric side was microinfused with saline, sham operated, or left intact. Striatal effects were analyzed within (he tral extent beginning at the striatal dorsal border and ending $6.6 \mathrm{~mm}$ below the skull (dotted area of $a$ ). This area, corresponding to the DLS, was initially compared with the area surrounding the TIP to assess nonspecific consequences of microinfusions. To evaluate the retrograde effects of lactacystin at the level of the substantia nigra, we analyzed the cell number in the nucleus along $0.8 \mathrm{~mm}$ rostrocaudally (from AP -5.60 to AP $-6.30 \mathrm{~mm}$; b). Microinfusion of lactacystin-epoxomycin produced ipsilateral

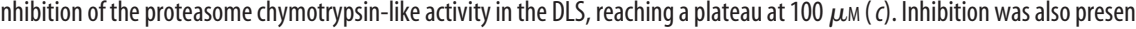
at the level of the TIP area without dose dependency; similar effects occur for trypsin ( $d$ ) and post-glutamyl peptidase $(e)$, which represent other catalytic units of the proteasome. In this respect, apart from higher efficacy of epoxomycin at low doses on the

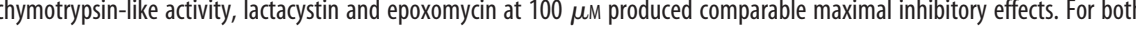
compounds, inhibition was no longer significant at $24 \mathrm{hr}$ ( $f$ ). RRF, Retro-rubral Field; SNC, substantia nigra pars compacta; SNR, substantia nigra pars reticulata. ${ }^{*} p<0.05$ compared with controls.

-5.6 ; ML, +1.5 ; and DV, -8.5 . This group served as positive control being challenged with the same drugs after the same time intervals.

\section{Statistical analysis}

Biochemical and morphological data (monoamine levels, enzyme activities, densitometric analysis, number of neurons per surface unit, percentage of apoptotic cells, and percentage of cell inclusions) were analyzed by using ANOVA with Sheffe's post hoc analysis.

\section{Results}

\section{In vivo experiments}

\section{Striatum}

Focal inhibition of the UP system within the rat neostriatum by microinfusing different doses of lactacystin-epoxomycin (Fig. 1a) produced a unilateral inhibition of the proteasome activity, reaching a plateau at $100 \mu \mathrm{M}$ (Fig. 1c); a similar effect was induced on other catalytic components of the proteasome, namely, the 


\section{Striatum}
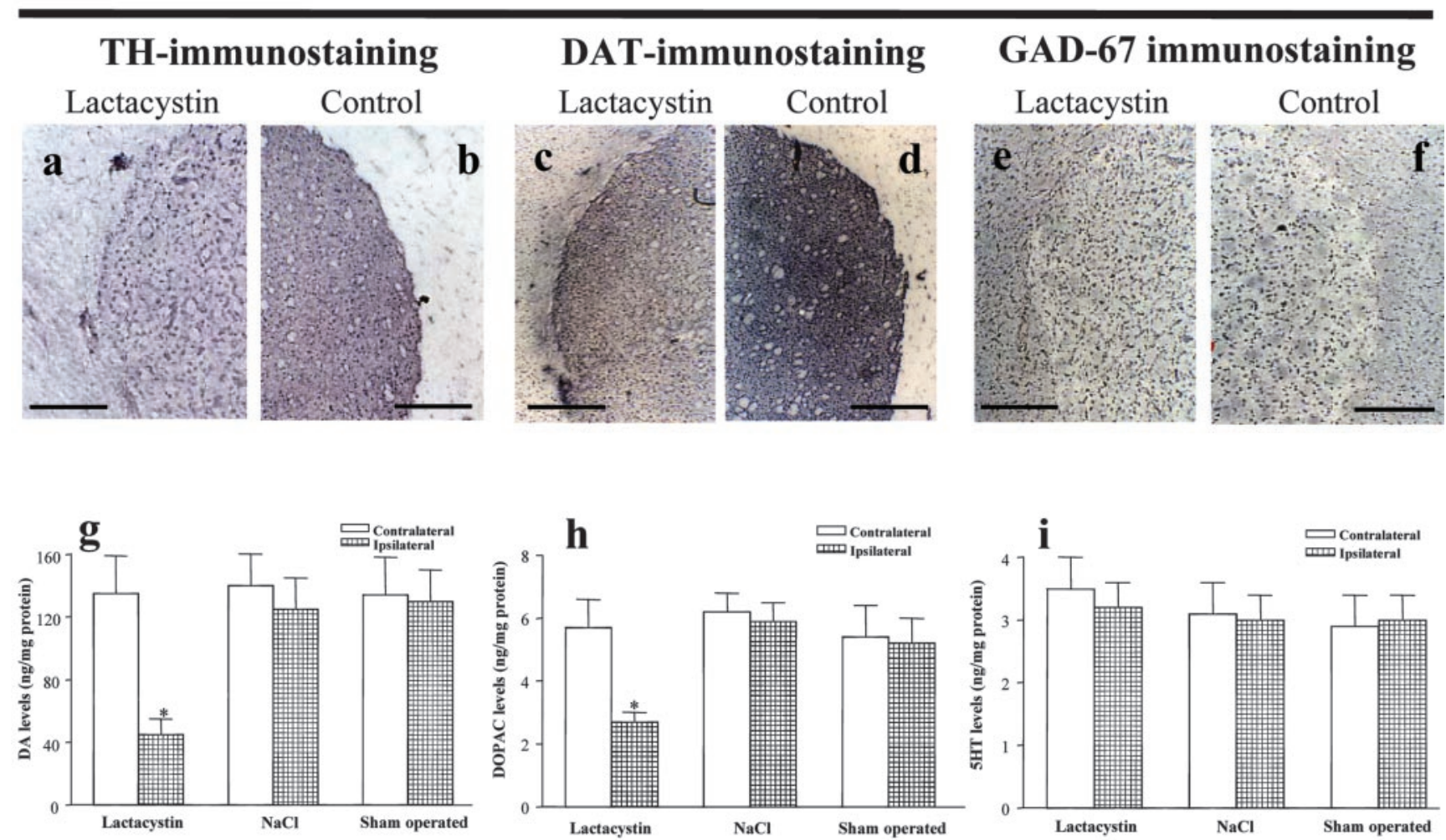

GFAP immunostaining
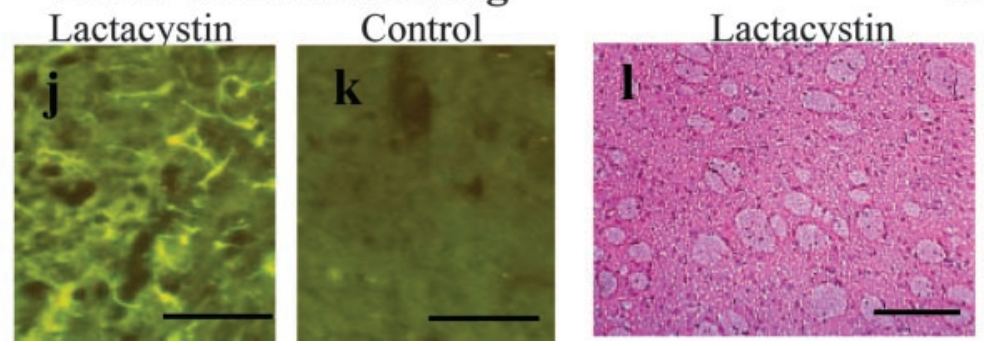

H\&E histochemistry
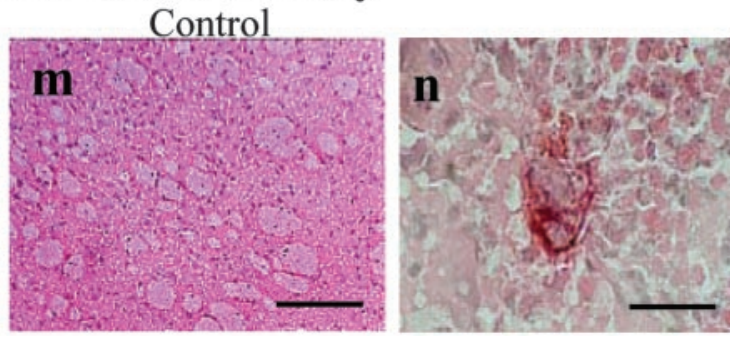

Figure 2. Striatal effects after microinfusion of proteasome inhibitors. Striatal microinfusions of proteasome inhibitors produces a selective loss of DA markers as shown here for lactacystin, which decreases TH immunostaining $(a)$ compared with controls $(b)$. This is comparable with the marked decrease of DAT immunostaining ( $c$, $d$, respectively). In contrast, no difference was observed concerning GAD-67 immunostaining between lactacystin-microinfused rats and controls $(e, f$, respectively). Biochemical analysis of striatal DA levels and its metabolite DOPAC confirmed a significant loss of DA terminals after lactacystin ( $g$, $h$, respectively), whereas 5 -HT levels were unchanged ( $i)$, thus confirming the DA-selective toxicity. The lactacystin-infused striatum was markedly stained for GFAP $(j)$ compared with the control side $(k)$, although no difference in the number of striatal cells was observed using H\&E staining $(I, m$, respectively), except from the area surrounding the tip of the cannula ( $n$ ). Scale bars: $a-f, 0.03 \mathrm{~mm} ; j-m, 0.01 \mathrm{~mm} ; n, 8 \mu \mathrm{m} .{ }^{*} p<0.05$ compared with controls.

trypsin (Fig. $1 d$ ) and post-glutamyl peptidase (Fig. 1e). Inhibition was no longer detectable at $24 \mathrm{hr}$ after striatal microinfusion, as shown in Figure $1 f$ for lactacystin. Lactacystin and epoxomycin produced comparable inhibitory effects. The selective neurotoxicity for the DA system was confirmed by representative immunohistochemistry showing a loss of TH (Fig. $2 a, b$ ) and DAT (Fig. $2 c, d)$, whereas GAD-67 immunostaining was similar to controls (Fig. 2e,f). Lactacystin $(100 \mu \mathrm{M})$ induced specific loss of DA levels in the ipsilateral striatum (Fig. $2 g$ ), similar to what produced by epoxomycin (Table 1); analogous effects were produced on striatal DOPAC levels (Fig. $2 h$ ), whereas no effects were produced on striatal 5-HT levels (Fig. 2i). Lower doses of proteasome inhibitors (not sufficient to inhibit the enzyme activity) did not produce significant neurotoxicity (as occurring in vitro; see below).

Semiquantitative densitometry from $20-\mu \mathrm{m}$-thick 10 serial slides of DLS from eight rats per group confirmed a significant loss of TH and DAT immunostaining, whereas no difference in the number of GAD-67-immunopositive striatal cells was observed. The loss of striatal DA terminals was accompanied by increased GFAP immunostaining (Fig. 2j,k), whereas no difference in the total cell number was detectable after striatal H\&E (Fig. $2 l, m$ ), thus demonstrating the integrity of the large population of striatal cells, except from a limited area of nonspecific damage surrounding the tip of the injection cannula (Fig. $2 n$ ). This striatal region, made of necrotic, mechanically disrupted tissue, was present also in saline-injected rats, and, apart from measuring the inhibition of chymotrypsin-like activity (TIP area compared with the DLS) (Fig. 1c), it was not included in the striatal field that was selected to measure focal effects of lactacystin-epoxomycin (Fig. 1a) (see also Materials and Methods). 
Table 1. Pharmacological modulation of proteasome inhibitor-induced striatal DA and TH cell loss

\begin{tabular}{lccc}
\hline & \multirow{2}{*}{$\begin{array}{l}\text { Striatal DA levels } \\
\text { (\% of control) }\end{array}$} & \multicolumn{2}{l}{ TH-positive nigral cells (\% of control) } \\
\cline { 3 - 4 } Treatment & DLS & Dorsal tier & Ventral tier \\
\hline Lactacystin & $32.2 \pm 6.0^{*}$ & $61.4 \pm 7.0^{*}$ & $23.1 \pm 2.8^{*}$ \\
Epoxomycin & $40.9 \pm 6.3^{*}$ & $55.1 \pm 4.9^{*}$ & $28.2 \pm 2.9^{*}$ \\
L-DOPA & $113.6 \pm 8$ & $105.4 \pm 7.9$ & $96.1 \pm 8.5$ \\
$\alpha$-MpT & $95.2 \pm 6.8$ & $98.5 \pm 9.3$ & $107.8 \pm 6.3$ \\
Pargyline & $102.5 \pm 1.7$ & $92.9 \pm 6.5$ & $91.4 \pm 4.6$ \\
Lactacystin plus $\alpha$-MpT & $85.2 \pm 11^{* *}$ & $88.4 \pm 6.5^{* *}$ & $83.7 \pm 7.2^{* *}$ \\
Epoxomycin plus $\alpha$-MpT & $93.1 \pm 12.5^{* *}$ & $77.6 \pm 7.2^{* *}$ & $78.2 \pm 7.9^{* *}$ \\
Lactacystin plus L-DOPA & $15.9 \pm 2.8^{* *}$ & $41.7 \pm 5.8^{* *}$ & $12.1 \pm 1.1^{* *}$ \\
Epoxomycin plus L-DOPA & $29.6 \pm 3.0^{* *}$ & $27.1 \pm 3.5$ & $14.2 \pm 2.2^{*}$ \\
Lactacystin plus pargyline & $26.0 \pm 3.5^{* *}$ & $52.1 \pm 4.8$ & $12.5 \pm 2.4^{* *}$ \\
Epoxomycin plus pargyline & $28.6 \pm 2.1^{* *}$ & $33.1 \pm 4.5$ & $15.7 \pm 3.2^{* *}$ \\
\hline Strat
\end{tabular}

Striatal effects were measured from the DLS microinfused with epoxomycin-lactacystin (Fig. 1a) or the controlateral DLS microinfused with saline (controls). Striatal DA levels were obtained from striatal homogenates of DLS. Nigral effects were measured on $20-\mu \mathrm{m}$-thick sections from 10 serial slides of substantia nigra along the rostrocaudal exent shown in Figure $1 b$. TH-Immunostained cells were counted from eight rats per group from the nigra ipsilateral to the microinfused striatum, and the contralateral nigra (ipsilateral to the striatum microinfused with saline) served as control. We found that intrastriatal infusion of proteasome inhibitors produced a significant loss of striatal DA levels and ipsilateral retrograde loss of nigral TH-immunostained cells. This effect was more pronounced in the ventral compared with the dorsal part of the substantia nigra. Lactacystin and epoxomycin were infused th the concentration of $100 \mu \mathrm{m}$ on the basis of the dose-response experiments reported in Results. L-DOPA was administered as methyl--LDOPA hydrochloride ( $100 \mathrm{mg} / \mathrm{kg}$, free base), $\alpha$-MpT was microinfused at the dose of $150 \mathrm{mg} / \mathrm{kg}$, and pargyline was injected at the dose of $75 \mathrm{mg} / \mathrm{kg}$. These compounds had no effects when injected alone; however, $\alpha$-MpT prevented and both L-DOPA and pargyline worsened the deleterious effects produced by proteasome inhibition. Values are expressed as percentage of controls. ${ }^{*} p<0.05$ compared with controls. ${ }^{* *} p<0.05$ compared with lactacystin or epoxomycin alone.

\section{Substantia nigra}

Cell loss. Effects of striatal lactacystin-epoxomycin infusions could be detected also in the ipsilateral mesencephalon, which was sampled as described in Figure $1 b$ (see Materials and Methods). In particular, in Figure 3, representative pictures show the loss of nigral cells ipsilateral to the microinfused striatum. The amount of cell loss measured by counting H\&E cells was significant in the ipsilateral nigra (Fig. $3 a$ ). This effect was also evident when measuring the number of TH-positive neurons (Table 1), showing that, within the substantia nigra pars compacta $(\mathrm{SNpc})$, the ventral tier exhibited a cell loss that was more severe compared with the dorsal part. Striatal infusions of lactacystin or epoxomycin also produced significant apoptosis (measured by light microscopy and TEM), which again was more evident in the ventral compared with the dorsal tier of the substantia nigra (Fig. $3 b$ ). The nigral cell loss measured in Figure $3 a$ is shown by representative micrographs of H\&E-stained substantia nigra ipsilateral (Fig. 3c) or contralateral (Fig. $3 d$ ) to the microinfused striatum. Among TH-positive neurons, those belonging to the ipsilateral SNpc were markedly affected compared with those belonging to the contralateral side (Fig. $3 e$, frespectively; Table 1). Again, in the ipsilateral side, we could measure a significant DA loss compared with the contralateral vehicle-infused, or sham, or non-operated side (data not shown). In contrast, $\mathrm{TH}$-positive neurons belonging to the ventral tegmental area (VTA) of mesencephalon were spared in both sides (Fig. $3 g, h$, respectively). In the substantia nigra ipsilateral to the microinfused striatum, we could detect degenerating neurons using the Fluoro Jade-B technique (Fig. 3i).

Striatal microinfusion of epoxomycin led to similar results in the ipsilateral substantia nigra. In Figure 3j, a representative micrograph shows the decrease of $\mathrm{TH}$ immunofluorescence in nigral neurons within the microinfused side, thus contrasting with intense $\mathrm{TH}$ immunofluorescence observed in the contralateral side (Fig. 3k), as measured in Table 1. Epoxomycin-induced apoptotic cells (already counted in Fig. $3 b$ ) are shown by a representative Hoechst-33258 staining (Fig. 3l), which differ markedly from what was observed in the contralateral side (Fig. $3 m$ ). Occurrence of apoptosis in these dying ipsilateral nigral neurons was validated by the gold standard (transmission electron microscopy) (Fig. 3n).

Neuronal inclusions. The lesioned side observed at light microscopy revealed intracellular inclusions that stained for parkin (Fig. 4a), $\alpha$-synuclein (Fig. 4b), ubiquitin (Fig. 4c), and the ubiquitin-activating enzyme E1 (Fig. 4d). When observed at transmission immunoelectron microscopy, we found that parkin-, $\alpha$-synuclein-, ubiquitin-, and E1-positive inclusions consisted of cytoplasmic bodies that were quite homogeneous concerning their shape and ultrastructure (Fig. $4 e-h$, respectively). They consisted of multilamellar whorls labeled with peroxidase- or immunogold-conjugated antibodies, which stained the same antigens detected at light microscopy (Fig. 4, compare $e-h$ with $a-d$ ). The same neuronal inclusions were detectable after epoxomycin. Therefore, both lactacystin or epoxomycin produced in vivo parkin-, $\alpha$-synuclein-, ubiquitin-, and E1-positive inclusions. Because previous in vitro studies demonstrated a partial colocalization of ubiquitin and $\alpha$-synuclein in lactacystin-treated cell cultures, we performed double staining in vivo for ubiquitin and $\alpha$-synuclein (Fig. $4 i-t$ ), in search of a potential parallelism between effects obtained in vivo and in vitro. In particular, we found that ubiquitin and $\alpha$-synuclein immunofluorescence was diffused in control nigral tissue, whereas it was clustered in nigral cells ipsilateral to the infused striatum. We found that a few nigral inclusions were double labeled for ubiquitin and $\alpha$-synuclein (Fig. $4 t$ ).

In summary, striatal UP inhibition in vivo led to selective toxicity for the nigrostriatal DA pathway. This consists of loss of striatal DA terminals joined with retrograde cell death (similar to what occurs after striatal infusion of 6-OHDA). Spared ipsilateral nigral cells developed neuronal inclusions because the structure of cytoplasmic whorls stained for components of the UP system and for the UP substrate $\alpha$-synuclein. Within microinfused striata, both lactacystin and epoxomycin produced inhibition of chymotrypsin, trypsin, and post-glutamyl peptidase activity. This inhibition was more effective for epoxomycin on chymotrypsinlike activity.

An additional point to be addressed was to explain why a diffuse dysfunction of the UP system is responsible for the selective toxicity to DA neurons, and the mechanisms (or the molecule) underlying this specificity. Because the first feature that characterizes DA neurons is DA itself, we studied whether inhibition of DA synthesis might lead to a protection against neurotoxicity induced by lactacystin-epoxomycin striatal infusions. Therefore, we administered the TH inhibitor $\alpha \mathrm{MpT}(150 \mathrm{mg} / \mathrm{kg}$ ) $4 \mathrm{hr}$ before striatal infusions, and we found a significant protection against nigrostriatal damage by measuring striatal DA levels and TH-positive nigral neurons (Table 1). Conversely, injecting the DA precursor L-DOPA (100 mg/kg) or blocking DA metabolism by administering the monoamine oxidase inhibitor pargyline $(75 \mathrm{mg} / \mathrm{kg})$ produced an enhancement of the neurotoxicity produced by proteasome inhibitors (Table 1).

To characterize this effect more in depth, we examined the role of DA in modulating cell death and lactacystin-induced inclusions in PC12 cells. In fact, this is a simple model to examine the role of DA metabolism during proteasome inhibition. In particular, profiting from in vitro conditions, we combined biochemistry with morphology to study more extensively how changes of DA metabolism could modify cell death and development of inclusions. As a preliminary step, we reproduced in vitro 


\section{Substantia Nigra (cell loss)}
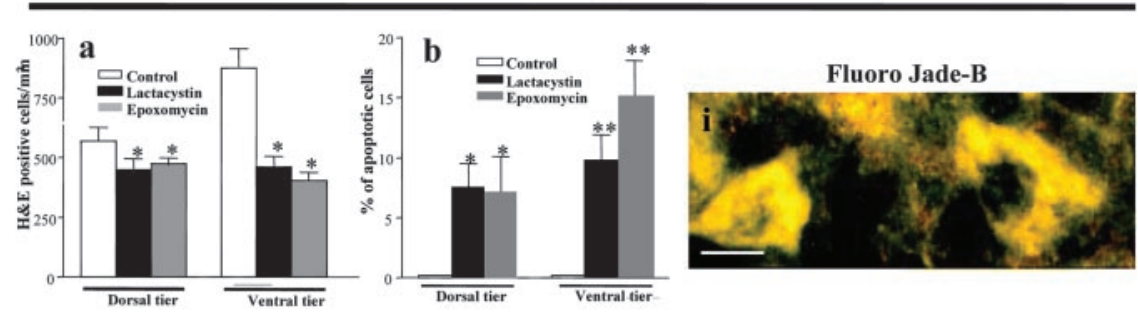

Lactacystin

Control

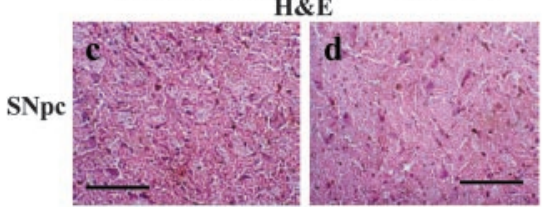

TH
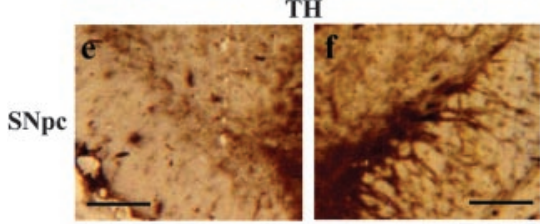

VTA
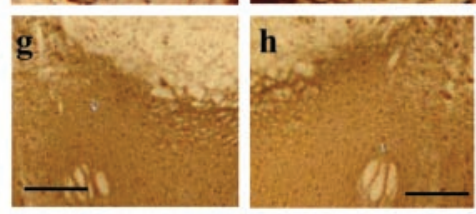

Epoxomycin

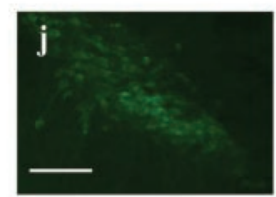

Hoechst-332
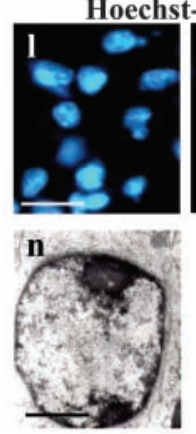

Control

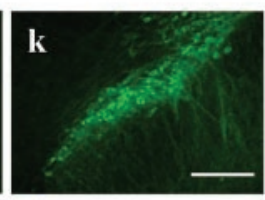

m

Figure 3. Retrograde nigral cell loss after striatal microinfusion of proteasome inhibitors. Striatal proteasome inhibition produces significant ipsilateral retrograde neuronal loss compared with contralateral substantia nigra when counting H\&Estained 20 - $\mu \mathrm{m}$-thick sections from 10 serial slides from eight rats per group $(a)$. This ipsilateral cell loss was accompanied by histochemical and electron microscopic evidence of a significant number of apoptotic neurons, which were more abundant in the ventral compared with the dorsal tier $(b)$. The apoptotic effects produced by striatal epoxomycin-lactacystin microinfusions were measured by counting the percentage of apoptotic cells visualized in 10 serial $20 \mu \mathrm{m}$ slides through the rostrocaudal nigral extent. Representative H\&E staining shows nigral neuronal loss and shrinkage compared with control ( $c$, $d$, respectively). Similarly, $\mathrm{TH}$ immunostaining in the SNpc ipsilateral to the injected striatum was markedly depleted compared with the contralateral side $(e, f$, respectively). No difference was visible between the VTAs $(g, h)$. In the ipsilateral SNpc, Fluoro-Jade B produced a marked yellow staining of degenerating neurons ( $i)$. Representative TH immunofluorescence from the SNpcipsilateral $(j)$ and contralateral $(k)$ to the striatum microinfused with the proteasome inhibitor epoxomycin, which selectively blocks the chymotrypsin-like activity of the proteasome. In the ipsilateral SNpc, the fluorescent method with bisbenzimide trihydrochloride (Hoechst-33258) reveals a few apoptotic neurons with condensed chromatin as typical for apoptotic cells $(I)$, contrasting with the contralateral side, which does not show apoptotic cells $(m)$. Again, in the ipsilateral SNpc, apoptotic cells were revealed using transmission electron microscopy $(n)$. The numerical data referring to these representative pictures $(I-n)$ were reported in the histogram of $b$. Scale bars: $c, d, 0.02 \mathrm{~mm} ; e-h, 0.01 \mathrm{~mm} ; i, 10 \mu \mathrm{m} ; j, k, 15 \mu \mathrm{m} ; I, m, 25 \mu \mathrm{m} ; n, 2 \mu \mathrm{m} .{ }^{*} p<0.05$ compared with controls.

cell inclusions and cell death observed in vivo after proteasome inhibition.

\section{In vitro experiments}

\section{Proteasome inhibition}

Increasing the dose of lactacystin and epoxomycin from 0.01 to $20 \mu \mathrm{M}$ led to a progressive inhibition of the chymotrypsin, trypsin-like, and post-glutamyl peptidase activity, which, at low doses, was more pronounced concerning the inhibition of chymotrypsin-like activity induced by epoxomycin (Fig. $5 a-c$ ).

\section{Fine structure of inclusions}

We found that exposure of PC12 cells to lactacystin or epoxomycin reproduced intracellular inclusions, as reported previously at light microscopy (including confocal analysis) (Rideout et al., 2001; McNaught et al., 2002a). These inclusions are similar to those that we observed in vivo. In fact, when observed at light microscopy, lactacystin-treated PC12 cells, similar to nigral neurons, developed E1-, ubiquitin-, $\alpha$-synuclein-, and parkin-immunopositive aggregates compared with their control cells (Fig. $5 d-k$ ). We found that inclusions produced in vitro possessed the same ultrastructure of those occurring in vivo (Fig. 5l).

When increasing the dose of lactacystin (keeping constant, at $24 \mathrm{hr}$, the time of exposure) (Fig. $6 a$ ), from 0.1 to $50 \mu \mathrm{M}$, we found a dose-dependent increase of intracellular whorls, reaching a maximum in the percentage of cells containing whorls for a dose of lactacystin of $1 \mu \mathrm{M}$. However, an additional increase of lactacystin (ranging from 1 to $50 \mu \mathrm{M}$ ) produced a decrease in the amount of inclusions-containing cells (Fig. 6a). Decrease in lactacystininduced inclusions for higher doses occurred concomitantly with the progressive onset of apoptotic cells (Fig. 6, compare $a$, $b)$. These morphological effects follow up the dose-response for extracellular (medium) and intracellular (pellet) DA levels (Fig. 6c, $d$, respectively).

Mimicking whorls occurring in vivo, multilamellar bodies found in PC12 cells contained stained antigens related to the UP system (ubiquitin, parkin, E1, and the UP substrate $\alpha$-synuclein; data not shown). In addition, similar to those occurring in vivo, inclusions produced by lactacystin in PC12 cells were solely found in the cytoplasm (we never found nuclear inclusions from $10^{4}$ cells under observation). Interestingly, $\alpha$-synuclein was definitely more abundant in the filamentous component of the whorls.

\section{Apoptosis and DA levels}

Exposure to lactacystin, apart from producing inclusions, determined apoptotic cell death, as documented by staining with Hoechst-33258 (Fig. 6e,f) and validated by the gold standard (Fig. $6 g, h$, scanning electron microscopy; $i$, transmission), combined with DNA electrophoresis to detect laddering of nucleic acids (Fig. 6j,k). As mentioned above, the dose-response curve for lactacystin-induced apoptosis was shifted to the right compared with the dose-response curve for cellular inclusions (Fig. $6 b, a$, respectively); the same trend was observed for the dose-response curve for proteasome inhibition (Fig. $5 a-c$ ). When we analyzed the effects of various doses of lactacystin on the amount of DA in the cell pellets, we found a progressive decrease of DA levels that reached a plateau for doses of lactacystin between 1 and $10 \mu \mathrm{M}$ (Fig. $6 d$ ). In contrast, the dose-response curve for DA levels measured in the cell medium increased with the dose of lactacystin, showing again a plateau between 1 and $10 \mu \mathrm{M}$ (Fig. $6 c$ ). Intracellular and extracellular levels of DA metabolites maintained the same ratio, with DA levels ruling out a direct effect of lactacystin on monoamine oxidase or catechol methyl transferase. On the other hand, when administering a selective uptake inhibitor (GBR 12909) differing from lactacystin, we produced an increase of DA levels in the 
medium without changing the amount of intracellular DA (data not shown). This differentiates the biochemical effects induced by lactacystin from what was obtained by inhibiting DA uptake.

\section{Pharmacological modulation of}

lactacystin-induced toxicity

To disclose the role of DA in lactacystininduced intracellular whorls and apoptosis, we measured how additional drugs, specifically affecting DA metabolism, might modulate effects of lactacystin. We selected the DA-depleting agent reserpine, the irreversible, nonselective monoamine oxidase inhibitor pargyline, the DA precursor L-DOPA, the inhibitor of DA $\beta$-hydroxylase fusaric acid, and the inhibitor of DOPAdecarboxylase carbidopa. The dose of each compound was selected in pilot dose-response experiments. Once the dose was selected, before testing the effects of each drug on the neurotoxicity induced by lactacystin, we measured the effects on DA levels at the time of lactacystin administration. This is reported in Figure $7 a$ where measures are taken from cell pellet, in which DA levels represent a good estimation of intracellular DA compared with levels in the medium (data not shown). As reported, reserpine at a dose that depleted intracellular DA (Fig. 7a) did not produce inclusions or cell loss per se but abolished lactacystin-induced inclusions and cell death (Fig. $7 b, c$, respectively). This led to lactacystin-treated cells exposed previously to reserpine looking like controls (Fig. $7 d$ ). In contrast, the DA precursor L-DOPA produced a significant increase in intracellular DA levels (Fig. 7a) and dramatically enhanced both lactacystininduced electrondense inclusions and cell death (Fig. 7b,c,e,f). An analogous effect was obtained by inhibiting the conversion of DA into NE by using the DA $\beta$-hydroxylase inhibitor fusaric acid, which produced an increase in DA levels (Fig. 7a) accompanied by suppression of NE biosynthesis (data not shown) and, concomitantly, increase of intracellular inclusions and apoptosis (Fig. 7b,c,g,h). Similarly, the inhibitor of DA oxidative deamination pargyline was able to double DA levels (Fig. 7a) in the cell culture by inhibiting physiological DA metabolism (we also measured $85 \%$ loss of DOPAC from the cell culture; data not shown). This effect was accompanied by a parallel increase in the toxicity induced by lactacystin administration (Fig. $7 b, c, i, j)$. Pretreatment of PC12 with drugs modulating DA metabolism, apart from modifying the number of cells containing inclusions and percentage of apoptotic cells compared with lactacystin alone (Fig. $7 b, c, k, l$ ), slightly modified the morphology of the inclusions. For instance, combining L-DOPA and lactacystin produced cell inclusions with a marked electrondense core compared with lactacystin alone (Fig. 7, compare, $e, f$ with $k$, l, respectively). Administration of carbidopa did not modify the effects of lactacystin (data not shown).

\section{Turning behavior}

Whereas 8 of 10 of 6-OHDA-microinfused rats exhibited turning behavior (at least seven complete rotations per minute over 90 I-n, $20 \mu \mathrm{m} ; 0-t, 5 \mu \mathrm{m}$.

\section{Substantia Nigra (inclusions)}
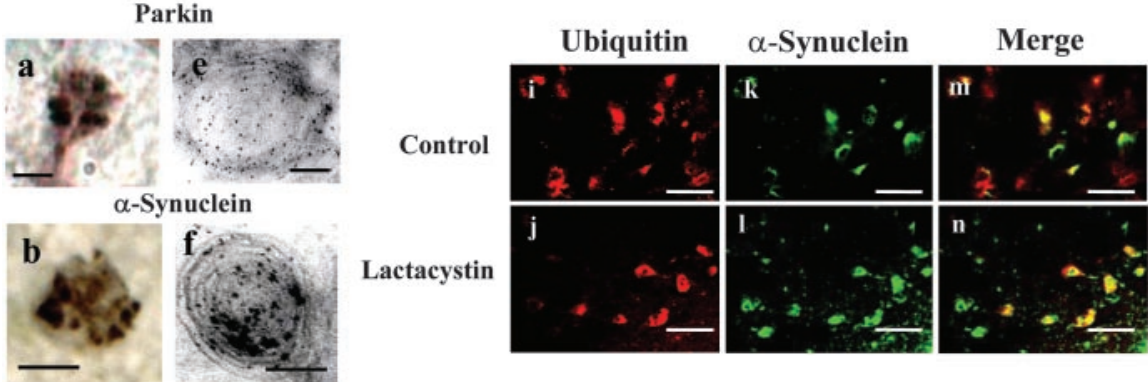

Ubiquitin

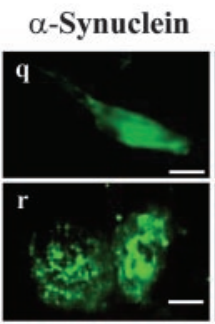

Merge

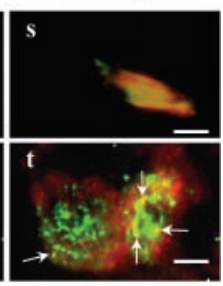

Figure 4. Neuronal inclusions in the SNpc ipsilateral to the microinfused striatum. In the SNpc ipsilateral to the microinfused

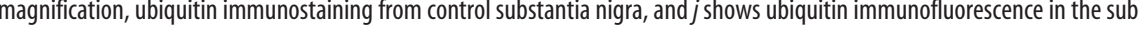
of merging in which few bright yellow spots (arrows) are visible ( $t$ ). Scale bars: $a, 5 \mu \mathrm{m} ; b, c, 10 \mu \mathrm{m} ; d, 30 \mu \mathrm{m} ; e-k, 0.15 \mu \mathrm{m}$

min observation time) at all time intervals, in rats microinfused with proteasome inhibitors, we could not detect any turning, at neither 7 nor 21 , or even at $28 \mathrm{~d}$. This is likely to be attributable to the fact that, to produce turning behavior, it is necessary that unilateral striatal DA loss reaches 90-95\% (Perese et al., 1989; Finberg et al., 1995). This was easily produced by 6-OHDA microinfusions, although we could never obtain such massive DA depletion after proteasome inhibitors.

\section{Discussion}

Parkinson's disease is a neurodegenerative disorder characterized by the selective loss of nigrostriatal DA neurons and the presence of LBs, proteinaceous cytosolic inclusions within various brain areas, with the DA cells of the SNpc being mostly affected (Pollanen et al., 1993; Lang and Lozano, 1998a,b). In recent years, a few genetic mutations were found to be responsible for inherited PD (Leroy et al., 1998), among these, mutations of $\alpha$-synuclein, UchL-1, and parkin (Polymeropoulos et al., 1997; Kitada et al., 1998; Leroy et al., 1998). These mutations decrease the enzymatic activity of the UP, although an impairment of the proteasome is also described in sporadic forms of PD (McNaught et al., 2001, 2003).

These studies suggest a tight association between impairment of the UP and occurrence of a selective damage to the nigrostriatal pathway featured by subcellular alterations similar to PD. If this is correct, then blockade of the UP system achieved by exog- 
PC 12 cells (I)

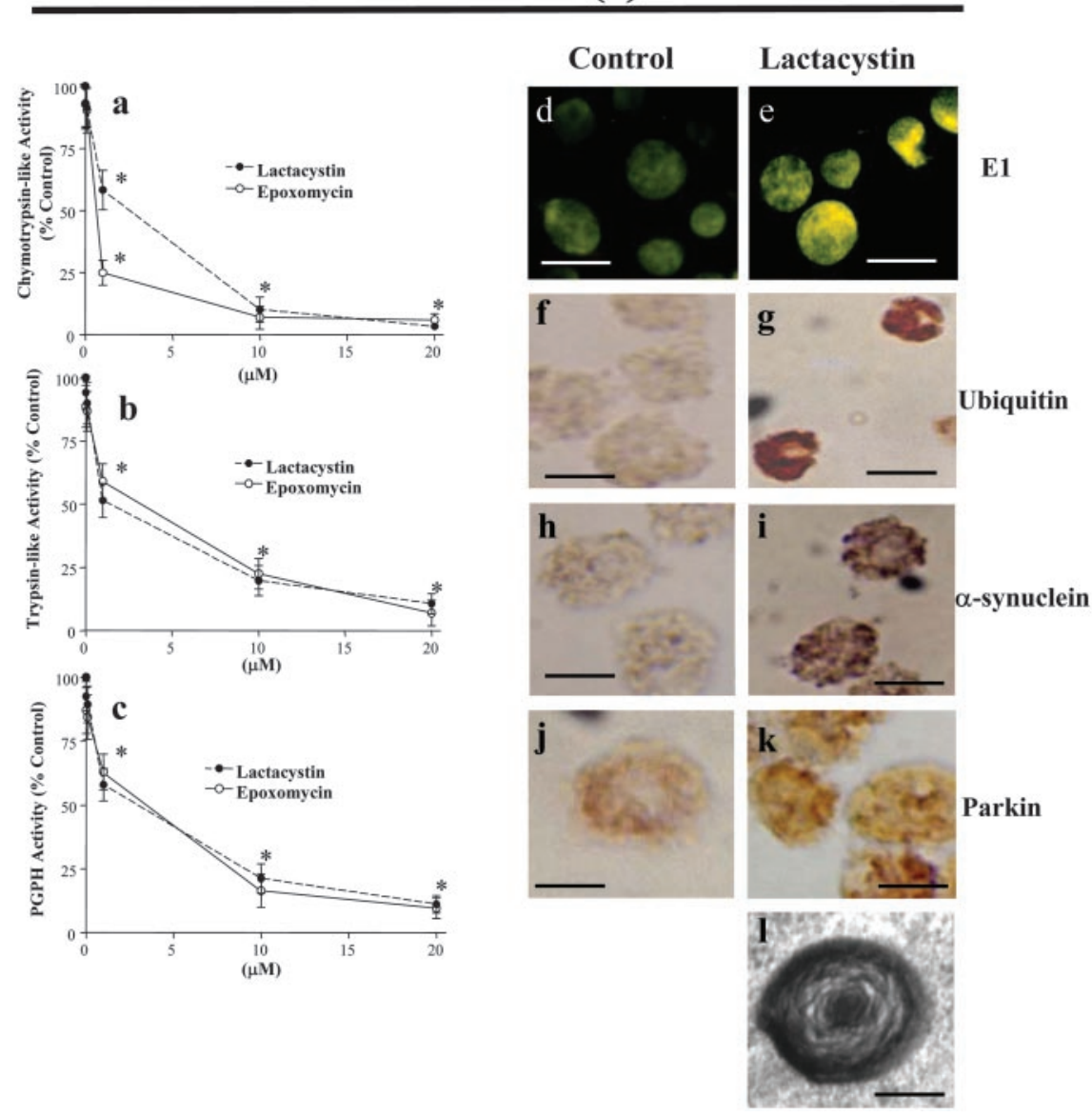

Figure 5. Dose-response effects of proteasome inhibitors and immunopositive cell inclusions. $a-c$ show the dose-response curves obtained in vitro for epoxomycin and lactacysin-induced inhibition of specific proteasome activities: chymotrypsin like (a), trypsin like $(b)$, and PGPH (c) measured after $4 \mathrm{hr}$ of exposure to both proteasome inhibitors. For both compounds, $10 \mu \mathrm{m}$ represents the concentration producing the maximal inhibition for each activity. Based on the results of these dose-response studies. PC12 cell were exposed to proteasome inhibitors (lactacystin, $10 \mu \mathrm{m}$, for $24 \mathrm{hr}$ ). After this treatment, PC12 cells developed cell aggregates stained for the ubiquitin-activating E1 enzyme $(d, e)$, ubiquitin $(f, g), \alpha$-synuclein $(h, i)$, and parkin $(j, k)$, as occurring in vivo within nigral cells (for comparison, see Fig. $4 a-g$ ). As shown in vivo, these intracellular aggregates when observed at TEM were shaped and structured as multilamellar membraneous whorls (I). Scale bars: $d-k, 20 \mu \mathrm{m} ; I, 200 \mathrm{~nm}$. ${ }^{*} p<$ 0.05 compared with controls.

enous pharmacological inhibitors should sort similar selective deleterious effects.

In the present study, we found that intrastriatal administration of lactacystin, at doses determining a significant and plateau inhibition of the proteasome activity, causes neuronal damage that is reproduced by epoxomycin (a more specific inhibitor of the chymotrypsin-like activity of the $20 \mathrm{~S}$ proteasome). This neuronal damage selectively affects striatal DA axons, sparing striatal serotonin levels and GABA neurons. The damage to striatal DA terminals was documented by the loss of DA and its metabolite (DOPAC), as well as the decrease in TH and DAT immunostaining in the microinfused striatum (common markers used to document striatal DA denervation) (Battaglia et al., 2002a,b). This was associated with marked DA cell loss within the ipsilateral $\mathrm{SNpc}$, affecting more severely the ventral tier and sparing the VTA of the mesencephalon. This was documented by a loss of $\mathrm{TH}$-immunostained and H\&E-stained cells, appearance of Fluoro Jade-B-positive neurons, and a marked decrease of nigral DA levels accompanied by apoptotic nigral neurons. We found the presence of $\alpha$-synuclein-, parkin-, E1-, and ubiquitin- immunostained inclusions in the nigrostriatal pathway. Altogether, these findings demonstrate that striatal UP inhibition leads to selective involvement of the DA component and produces a retrograde toxicity for nigral DA cells. Similar to lactacystin-induced inclusions occurring in vitro, in the present study, we found a few nigral inclusions in which ubiquitin and $\alpha$-synuclein colocalized. Our data provide the evidence for the selectivity, the shape, and the fine structure of nigrostriatal damage after striatal UP inhibition in vivo. In particular, we demonstrate occurrence of whorls within nigral cells that stain for parkin, ubiquitin, E1, and $\alpha$-synuclein. These intracellular inclusions, when observed at electron microscopy, resemble analogous inclusions that we observed in vivo after methamphetamine (F. Fornai, P. Lenzi, M. Gesi, P. Soldani, M. Ferrucci, G. Lazzeri, L. Capobianco, G. Battaglia, A. De Blasi, F. Nicoletti, and A. Paparelli, unpublished observations) or 3,4-methylenedioxymethamphetamine (Fornai et al., 2002) and described as vacuoles and autophagic granules at light microscopy in vitro after methamphetamine administration (Cubells et al., 1994; Larsen et al., 2002).

The lactacystin-epoxomycin-induced inclusions that we observed in vivo were exclusively cytoplasmic and never affected glial cells. Interestingly, $\alpha$-synuclein was definitely more abundant in the filamentous component of the whorls.

When reproduced in PC12 cells, we could detect at light microscopy similar cytoplasmic inclusions that, as described by Rideout et al. (2001), were positive for both ubiquitin and $\alpha$-synuclein, and they were stained with anti-E1 and parkin antibodies just like inclusions observed in vivo.

By using electron microscopy, we found that, also in PC12 cells, lactacystin-epoxomycin-induced inclusions appear as multilamellar whorls often featuring an electrondense core. These inclusions accumulated dose dependently in PC12 cells up to a plateau, occurring for a dose of UP inhibitor lower than what was necessary to induce maximal apoptosis. This suggests that only moderate doses of UP inhibitor determine the onset of inclusions, whereas increasing the dosage leads to cell death occurring for maximal proteasome inhibition as shown in vivo. Profiting from in vitro conditions, we searched for the biochemical steps (molecule) that might be crucial in provoking cell death and inclusions during a failure of the UP system. The selective effects on DA-containing structures that we observed in vivo after striatal microinfusions surprisingly matches the quite selective DA toxicity occurring in inherited PD when the mutation of UP-related components is ubiquitous. Therefore, we focused on the presence of DA and DA metabolites as a potential mechanism; this was confirmed by the protective effects on lactacystin-epoxomycin-induced striatal DA loss that we obtained by transient depletion of striatal DA pretreating rats with the TH inhibitor $\alpha \mathrm{MpT}, 4 \mathrm{hr}$ before microinfusion of the protea- 
some inhibitors. This was further demonstrated by the enhancement of neurotoxicity induced by drugs increasing DA (as either the DA precursor L-DOPA or the monoamine oxidase blocker pargyline).

When performing in vitro studies, we focused on the presence of endogenous DA as a neurotoxic factor. Endogenous DA was crucial for lactacystin-epoxomycininduced toxicity, because the use of the DA-depleting agent reserpine suppressed lactacystin-epoxomycin-induced whorls and apoptosis. In contrast, increasing DA levels by supplying the precursor L-DOPA produced an opposite effect by enhancing the number of inclusions. Similarly, blocking the conversion of DA to NE by using the DA $\beta$-hydroxylase inhibitor fusaric acid increased DA levels and lactacystininduced inclusions and apoptosis. This effect might be related to the spontaneous oxidation of DA to DA-quinones, because the blockade of enzymatic oxidative deamination using the nonselective monoamine oxidase inhibitor pargyline worsened neurotoxicity. This lends substance to a recent hypothesis on the occurrence of toxic adducts between DA-quinones and $\alpha$-synuclein as a critical biochemical step in PD (Conway et al., 2001; Sulzer, 2001). Accordingly, in PC12 cell cultures expressing mutant $\alpha$-synuclein, a severe impairment of the UP system was demonstrated (Stefanis et al., 2001). This is substantiated by the data of Sulzer et al. (2000) and by the ability of L-DOPA by itself to produce similar effects in PC12 cells. Finally, we could not suppress the formation of these potential autophagic inclusions by inhibiting the conversion from L-DOPA to DA with carbidopa.

The first typical feature that characterizes both PC12 and nigral cells is the ability to synthesize DA. Indeed, this peculiarity makes nigrostriatal DA neurons vulnerable to various neurotoxins, which increase the cytosolic DA content. This is the case of methamphetamine (Schmidt et al., 1985; Sulzer et al., 2000), malonate (Sonsalla et al., 1997; Moy et al., 2000), 1-methyl-4phenyl-1,2,3,6-tetrahydropyridine (Gainetdinov et al., 1998), or the absence of vesicular DA transporter, especially when joined with normal expression of membrane DAT (Gainetdinov et al., 1998; Jones et al., 1998; Fumagalli et al., 1999; Miller et al., 1999). There is a growing body of evidence that focuses on free cytosolic DA as a critical agent for DA-containing neurons. Our data confirm this evidence and suggest that the dysfunction of the clearing activity by the UP may not allow these cells to survive properly.

The dose-dependent increase in medium DA levels, concomitant with a reduction of both DA and DOPAC levels measured in the pellet, rules out an inhibition of monoamine oxidase activity (which was instead evident after treating the cells with pargyline); again, effects of lactacystin were different from what observed with the selective uptake inhibitor GBR 12909, and a change was compared with $1 \mu \mathrm{m}$ lactacystin.

\section{PC 12 cells (II)}
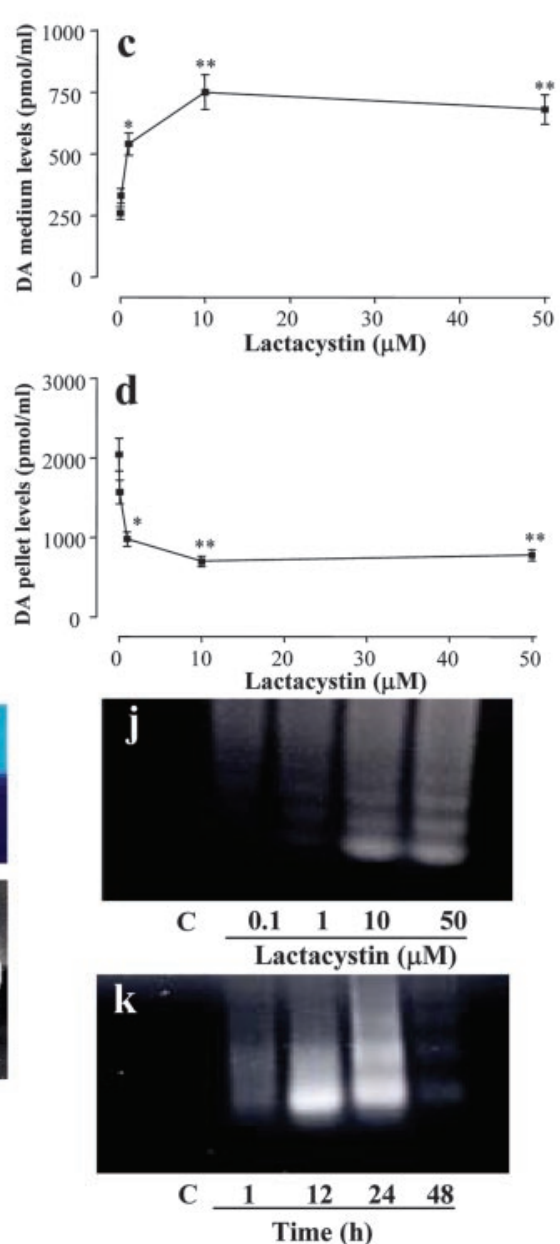

Figure 6. Morphological and biochemical effects induced by lactacystin in PC12 cells. a reports a dose-response study for lactacystin-induced inclusions, and $b$ shows the dose response for lactacystin-induced apoptosis. We also measured, in both the cell medium $(c)$ and the pellet $(d)$, the dose-response effects of lactacystin on DA levels. The same dose-response curve was (

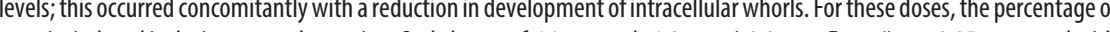
controls, and ${ }^{* *} p<0.05$ compared with $0.1 \mu \mathrm{m}$ lactacystin. For $b-d{ }^{*} p<0.05$ compared with controls, and ${ }^{* *} p<0.05$

not found in the rate of NE synthesis, ruling out an effect on DA $\beta$-hydroxylase. It is likely that these changes in DA levels that we measured in the pellet are attributable to cell death; this is also expected to produce leaking of proportional amounts of DA and its metabolites in the cell medium, consistent with our measurements.

In fact, our data confirm that proteasome inhibition is accompanied by apoptosis both in vivo and in vitro, and we observed comparable dose responses for percentage of apoptotic cells, proteasome inhibition, the decrease in DA content in the cell pellets, and the increase in DA levels within the cell medium.

In this study, in vivo and in vitro data joined together indicate that DA containing cells represent, per se, a system in a delicate metabolic equilibrium. This instability is an intrinsic propriety of 


\section{PC 12 cells (III)}
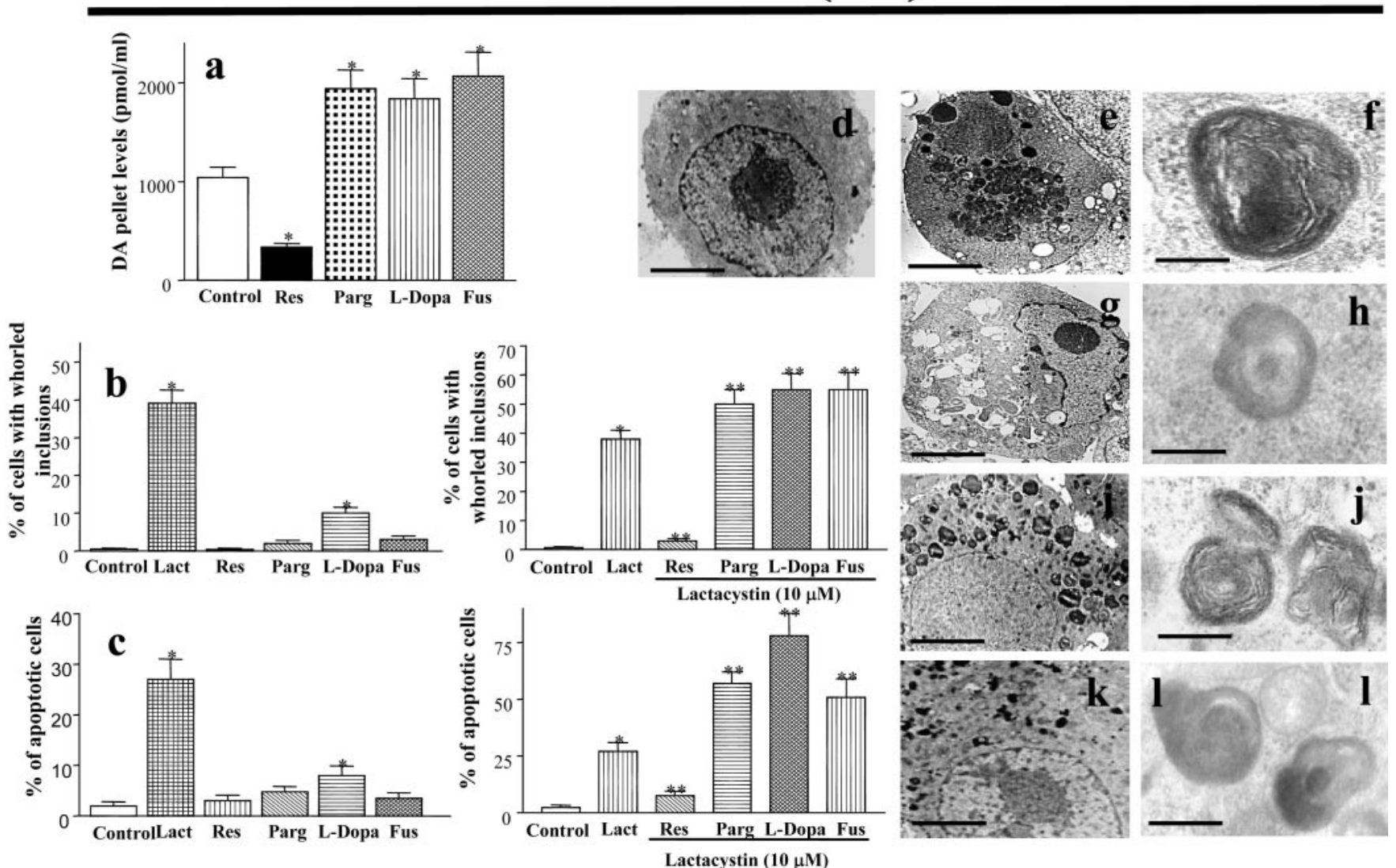

Figure 7. Pharmacological modulation of cellular inclusions and apoptotic cell death induced by proteasome inhibitors. Various drugs affecting DA metabolism ( $(a)$ were used at doses known to produce their maximal effects without losing selectivity (see Materials and Methods). Before measuring the effects on lactacystin-induced toxicity, each drug was tested for its effects on intracellular DA levels $(a)$ (DA levels in the medium or intracellular and extracellular levels of DA metabolites were also obtained, but they were not reported here). $b$ and $c$ (left column) show the potential of each drug to induce cell inclusions or apoptosis, respectively, when administered alone compared with lactacystin. When the DA-depleting agent reserpine (50 $\mathrm{nm)} \mathrm{was} \mathrm{administered} 4 \mathrm{hr}$ before lactacystin, DA levels were markedly suppressed ( $a$ ), and lactacystin-induced inclusions $(b)$ and apoptotic cells $(c)$ were reduced (right column). When examined at TEM, reserpine plus lactacystintreated cells $(d)$ were devoided of inclusions or apoptotic phenomena, markedly differing from the ultrastructure of PC12 cells treated with lactacystin alone $(k, I)$. Conversely, adding L-DOPA at a dose of $500 \mu \mathrm{m}$ to the cell culture significantly increased DA levels $(a)$, the number of inclusions induced by the combined treatment $(b)$, and the number of apoptotic cells $(c)$. When observed at TEM, these cell cultures possessed several inclusions occurring together with apoptotic events (e). L-DOPA plus lactacystin-induced inclusions were characterized by a pronounced electrondensity $(e$, $f)$. Also, the monoamine oxidase inhibitor pargyline (100 $\mu \mathrm{M})$ significantly increased DA levels $(a)$, together with an increase in both lactacystin-induced inclusions $(b, h)$ and apoptotic cells $(c, g)$. Similarly, fusaric acid $(1 \mu \mathrm{M})$, by inhibiting conversion of DA to NE, augmented DA levels ( $a$ ) and lactacystin-induced inclusions $(b, i, j)$, as well as apoptosis $(c)$. Scale bars: $d-k, 0.4 \mu \mathrm{m} ; f, 105 \mathrm{~nm}$; $h-I, 150$ nm. ${ }^{*} p<0.05$ compared with controls; ${ }^{* *} p<0.05$ compared with lactacystin.

these cells, which is attributable to the presence of high levels of DA in their cytosol (Miller et al., 1999; Sulzer et al., 2000; Conway et al., 2001). Indeed, DA metabolism is an important source of oxidative stress. Recently, DA metabolites were found to interact with $\alpha$-synuclein to produce toxic protofibrils (Conway et al., 2001; Sulzer, 2001), which are potential substrate for the UP pathway. Within this context, DA cells are critically bound to an efficient UP system to clear DA-related oxidative products. In line with this, it seems worthy to try proteasome inhibitors in $\alpha$-synuclein knock-out mice.

In the proteasome literature, there are interesting observations that show similar whorls after lactacystin in the parasite Toxoplasma gondii (Shaw et al., 2000). This suggests that the UP system represents a very ancestral pathway, which leads to highly conserved intracellular inclusions when its function is impaired. Indeed, translating insight from parasitology and immunology to neuroscience leads to unexpected analogies between the ultrastructure of UP inhibitor-induced inclusions in neurons and those occurring in various parasites, as well as the involvement of the UP system during an immunological response (Laszlo et al., 1991; DeMartino and Slaughter 1999; Schwarz et al., 2000). These analogies create an intriguing hypothesis on the basic significance of the UP system and the ancient origin of the DA nigrostriatal system and its tendency to spontaneous degeneration.

\section{References}

Battaglia G, Busceti CL, Cuomo L, Giorgi FS, Orzi F, De Blasi A, Nicoletti F, Ruggieri S, Fornai F (2002a) Continuous subcutaneous infusion of apomorphine rescues nigro-striatal dopaminergic terminals following MPTP injection in mice. Neuropharmacology 42:367-373.

Battaglia G, Fornai F, Busceti CL, Aloisi G, Cerrito F, De Blasi A, Melchiorri D, Nicoletti F (2002b) Selective blockade of mGlu5 metabotropic glutamate receptors is protective against methamphetamine neurotoxicity. J Neurosci 22:2135-2141.

Chung KKK, Dawson VL, Dawson TM (2001) The role of the ubiquitinproteasomal pathway in Parkinson's disease and other neurodegenerative disorders. Trends Neurosci 24:S7-S14.

Ciechanover A, Orian A, Schwartz AL (2000) Ubiquitin-mediated proteolysis: biological regulation via destruction. BioEssays 22:442-451.

Conway KA, Rochet JC, Bieganski RM, Lansbury Jr PT (2001) Kinetic sta- 
bilization of the alpha-synuclein protofibril by a dopamine-alphasynuclein adduct. Science 294:1346-1349.

Cubells JF, Rayport S, Rajendran G, Sulzer D (1994) Methamphetamine neurotoxicity involves vacuolation of endocytic organelles and dopaminedependent intracellular oxidative stress. J Neurosci 14:2260-2271.

DeMartino GN, Slaughter CA (1999) The proteasome, a novel protease regulated by multiple mechanisms. J Biol Chem 274:22123-22126.

Finberg JPM, Wang J, Goldstein DS, Kopin IJ, Bankiewicz KS (1995) Influence of selective inhibition of monoamine oxidase A and B on striatal metabolism of L-DOPA in hemiparkinsonian rats. J Neurochem 65:1213-1220.

Fornai F, Chen K, Giorgi FS, Gesi M, Alessandrì MG, Shih JC (1999) Striatal dopamine metabolism in monoamine oxidase B-deficient mice: a brain dialysis study. J Neurochem 73:2434-2440.

Fornai F, Gesi M, Saviozzi M, Lenzi P, Piaggi S, Ferrucci M, Casini A (2001) Immunohistochemical evidence and ultrastructural compartmentalization of a new antioxidant enzyme in the rat substantia nigra. J Neurocytol 30:97-105.

Fornai F, Gesi M, Lenzi P, Ferrucci M, Pellegrini A, Ruggieri S, Casini A, Paparelli A (2002) Striatal post-synaptic ultrastructural alterations following methylenedioxymethamphetamine administration. Ann NY Acad Sci 965:381-398.

Forno L (1996) Neuropathology of Parkinson's disease. J Neuropathol Exp Neurol 55:259-272.

Fumagalli F, Gainetdinov RR, Wang YM, Valenzano KJ, Miller GW, Caron MG (1999) Increased metamphetamine neurotoxicity in heterozygous vesicular monamine transporter 2 knock-out mice. J Neurosci 19:2424-2431.

Gai WP, Yuan HX, Li XQ, Power JT, Blumbergs PC, Jensen PH (2000) In situ and in vitro study of colocalization and segregation of $\alpha$-synuclein, ubiquitin, and lipids in Lewy bodies. Exp Neurol 166:324-333.

Gainetdinov RR, Fumagalli F, Wang YM, Jones SR, Levey AI, Miller GW, Caron MG (1998) Increased MPTP neurotoxicity in vesicular monamine transporter 2 heterozygote knock-out mice. J Neurochem 70:1973-1978.

Haimovitz-Friedman A, Kan CC, Ehleiter D, Persaud RS, McLoughlin M, Fuks Z, Kolesnick RN (1994) Ionizing radiation acys on cellular membranes to generate ceramide and initiate apoptosis. J Exp Med 180:525-535.

Jones SR, Gainetdinov RR, Wightman RM, Caron MG (1998) Mechanism of amphetamine action revealed in mice lacking the dopamine transporter. J Neurosci 18:1979-1986.

Kitada T, Asakawa S, Hattori N, Matsumine H, Yamamura Y, Minoshima S, Yokoki M, Mizuno Y, Shimizu N (1998) Mutations in the parkin gene cause autosomal recessive juvenile parkinsonism. Nature 392:605-608.

Lang AE, Lozano AM (1998a) Parkinson's disease. First of two parts. N Engl J Med 339:1044-1053.

Lang AE, Lozano AM (1998b) Parkinson's disease. Second of two parts. N Engl J Med 339:1130-1143.

Lansbury Jr PT, Brice A (2002) Genetics of Parkinson's disease and biochemical studies of implicated gene products. Curr Opin Genet Dev 12:299-306.

Larsen KE, Fon EA, Hastings TG, Edwards RH, Sulzer D (2002) Methamphetamine-induced degeneration of dopaminergic neurons involves autophagy and upregulation of dopamine synthesis. J Neurosci 22:8951-8960.

Laszlo L, Tuckwell J, Self T, Lowe J, Landon M, Smith S, Hawthorne JN, Mayer RJ (1991) The latent membrane protein-1 in Epstein-Barr virustransformed lymphoblastoid cells is found with ubiquitin-protein conjugates and heat-shock protein 70 in lysosomes oriented around the microtubule organizing centre. J Pathol 164:203-214.

Leroy E, Boyer R, Auburger G, Leube B, Ulm G, Mezey E, Harta G, Brownstein MJ, Jonnalagada S, Chernova T, Dehejia A, Lavedan C, Gasser T, Steinbach PJ, Wilkinson KD, Polymeropoulos MH (1998) The ubiquitin pathway in Parkinson's disease. Nature 395:451-452.

Liu Y, Fallon L, Lashuel HA, Liu Z, Lansbury Jr PT (2002) The UCH-L1 gene encodes two opposing enzymatic activities that affect alpha-synuclein degradation and Parkinson's disease susceptibility. Cell 111:209-218.

McNaught KS, Olanow CW, Halliwell B, Isacson O, Jenner P (2001) Failure of the ubiquitin-proteasome system in Parkinson's disease. Nat Rev Neurosci 2:589-594.

McNaught KS, Mytilineou C, JnoBaptiste R, Yabut J, Shashidharan P, Jenner
P, Olanow CW (2002a) Impairment of the ubiquitin-proteasome system causes dopaminergic cell death and inclusion body formation in ventral mesencephalic cultures. J Neurochem 81:301-306.

McNaught KS, Shashidharan P, Perl DP, Jenner P, Olanow CW (2002b) Aggresome-related biogenesis of Lewy bodies. Eur J Neurosci 16:2136-2148.

McNaught KS, Belizaire R, Isacson O, Jenner P, Olanow CW (2003) Altered proteasomal function in sporadic Parkinson's disease. Exp Neurol 179:38-46.

Miller GW, Gainetdinov RR, Levey AI, Caron MG (1999) Dopamine transporter and neuronal injury. Trends Pharmacol Sci 20:424-429.

Moy LY, Zeevalk GD, Sonsalla PK (2000) Role for dopamine in malonateinduced damage in vivo in striatum and in vitro in mesencephalic cultures. J Neurochem 74:1656-1665.

Paxinos G, Watson C (1986) The rat brain in stereotaxic coordinates. San Diego: Academic.

Perese DA, Ulman J, Viola J, Ewing SE, Bankiewicz KS (1989) A 6hydroxydopamine-induced selective parkinsonian rat model. Brain Res 273:45-51.

Pollanen MS, Dickson DW, Bergeron C (1993) Pathology and biology of the Lewy body. J Neuropathol Exp Neurol 52:183-191.

Polymeropoulos MH, Lavedan C, Leroy E, Ide SE, Dehejia A, Dutra A, Pike B, Root H, Rubenstein J, Boyer R, Stenroos ES, Chandrasekharappa S, Athanassiadou A, Papapetropoulos T, Johnson WG, Lazzarini AM, Duvoisin RC, Di Iorio G, Golbe LI, Nussbaum RL (1997) Mutation in the alphasynuclein gene identified in families with Parkinson's disease. Science 276:2045-2047.

Rideout HJ, Larsen KE, Sulzer D, Stefanis L (2001) Proteasomal inhibition leads to formation of ubiquitin/a-synuclein-immunoreactive inclusions in PC12 cells. J Neurochem 78:899-908.

Schmidt CJ, Ritter JK, Sonsalla PK, Hanson GR, Gibb JW (1985) Role of dopamine in the neurotoxic effects of metamphetamine. J Pharmacol Exp Ther 233:539-544.

Schmued LC, Hopkins KJ (2000) Fluoro-Jade B: a high affinity fluorescent marker for the localisation of neuronal degeneration. Brain Res 874:123-130.

Schwarz K, De Giuli R, Schmidtke G, Kostka S, Van Den Broek M, Kim KB, Crews CM, Kraft R, Groettrup M (2000) The selective proteasome inhibitors lactacystin and epoxomicin can be used to either up- or down-regulate antigen presentation at nontoxic doses. J Immunol 164:6147-6157.

Shaw MK, He CY, Roos DS, Tilney LG (2000) Proteasome inhibitors block intracellular growth and replication of Toxoplasma gondii. Parasitology 121:35-47.

Shenoy SK, McDonald PH, Kohout TA, Lefkowitz RJ (2001) Regulation of receptor fate by ubiquitination of activated $\beta 2$-adrenergic receptor and $\beta$-arrestin. Science 294:1307-1313.

Shimura H, Hattori N, Kubo S, Mizuno Y, Asakawa S, Minoshima S, Shimizu N, Iwai K, Chiba T, Tanaka K, Suzuki T (2000) Familial Parkinson disease gene product, parkin, is an ubiquitin-protein ligase. Nat Genet 25:302-305.

Shimura H, Schlossmacher MG, Hattori N, Frosch MP, Trockenbacher A, Schneider R, Mizuno Y, Kosik KS, Selkoe DJ (2001) Ubiquitination of a new form of a-synuclein by parkin from human brain: implications for Parkinson's disease. Science 293:263-269.

Sonsalla PK, Manzino L, Sinton CM, Liang CL, German DC, Zeevalk GD (1997) Inibition of striatal energy metabolism produces cell loss in the ipsilateral substantia nigra. Brain Res 773:223-226.

Spillantini MG, Schmidt ML, Lee VM, Trojanowski JQ, Jakes R, Goedert M (1997) Alpha-synuclein in Lewy bodies. Nature 388:839-840.

Steece-Collier K, Maries E, Kordower JH (2002) Etiology of Parkinson's disease: genetics and environment revisited. Proc Natl Acad Sci USA 99:13972-13974.

Stefanis L, Larsen KE, Rideout HJ, Sulzer D, Greene LA (2001) Expression of A53T mutant but not wild-type $\alpha$-synuclein in PC12 cells induces alterations of the ubiquitin-dependent degradation system, loss of dopamine release, and autophagic cell death. J Neurosci 21:9549-9560.

Sulzer D (2001) $\alpha$-synuclein and cytosolic dopamine: stabilizing a bad situation. Nat Med 7:1280-1282.

Sulzer D, Bogulavsky J, Larsen KE, Behr G, Karatekin E, Kleinman MH, Turro N, Krantz D, Edwards RH, Greene LA, Zecca L (2000) Neuromelanin biosynthesis is driven by excess cytosolic catecholamines not accumulates by synethic vesicles. Proc Natl Acad Sci USA 97:11869-11874. 